\title{
Alarm Calling Behavior of the Thirteen-Lined Ground Squirrel, Spermophilus tridecemlineatus
}

\author{
P.L. Schwagmeyer \\ Neuroscience Laboratory Building, University of Michigan, 1103 E. Huron, Ann Arbor, Michigan 48109, USA \\ Received December 5, 1979/Accepted April 25, 1980
}

Summary. Alarm calling in a population of thirteenlined ground squirrels, Spermophilus tridecemlineatus, was studied over a three-year period. Data on ground squirrel reactions to human and canine approaches and to the approach or presence of avian predators were used to quantify alarm calling behavior.

The results support the hypothesis that alarm calling in this species functions to warn genetic relatives. Human and canine approach-elicited calls were most frequently given by mothers and their recently emerged young; adult males and nonparous females rarely called. The onset of maternal calling coincided with the aboveground appearance of a mother's own litter, and both juvenile and maternal calling were terminated at approximately three weeks post-emergence. Alarm calls were rarely emitted during encounters with avian predators.

Alarm calling behavior in $S$. tridecemlineatus thus appeared to be dependent upon the presence of newly emerged juvenile relatives. To investigate whether the population structure of $S$. tridecemlineatus was perhaps incompatible with the evolution of alarm calling directed toward adult relatives, the distance between the home ranges of adult relatives and the distance over which the alarm vocalization is audible to ground squirrels were measured. The results revealed that females were likely to have adult relatives residing within audible range of the call.

\section{Introduction}

Several authors (Perrins 1968; Trivers 1971; Charnov and Krebs 1975; Dawkins 1976) have suggested that alarm calling could increase the probability that the caller will escape predation. Among group-living organisms, alarm calls would thus be expected to be given by any individual able to improve its chances of evading an approaching predator by vocalizing. An exception to this prediction might arise if the caller's avoidance of predation is at the expense of its neighbors due to confusion created by the call (Charnov and Krebs 1975) or the ventriloquial nature of the signal (Perrins 1968). If calling endangers conspecifics, it may be less prevalent among individuals with relatives nearby.

In contrast, alarm calling has also been proposed to function to protect genetic relatives of the caller from predators (Hamilton 1963, 1964; Maynard Smith 1965; Williams 1966). In this case, the behavior would be expected to be most prevalent among individuals whose relatives could be effectively warned by a call. The results of recent field studies on two ground squirrel species support this hypothesis. In both Spermophilus tereticaudus (Dunford 1977) and S. beldingi (Sherman 1977), adult females were reported to call more frequently than adult males. Both studies were conducted on populations in which females, but not males, tend to settle in the vicinity of their natal burrow; the observed sex differences in alarm calling thus correspond with sex differences in proximity of relatives.

The results of a field investigation of the alarm calling behavior of a third ground squirrel, S. tridecemlineatus, are reported here. Observation of the study population during 1976 revealed that ground squirrels appeared to call most frequently during June and July, when juveniles were first emerging from their natal burrows. Human and canine approaches to ground squirrels were made in 1977 and 1978 to quantify variation in alarm calling frequency with time during the season. Individual differences in frequency of calling were analyzed in terms of sex and reproductive status. The response of $S$. tridecemlineatus to avian predators was also investigated. Finally, the observed changes in frequency of occurrence of 
calling behavior within seasons were hypothesized to coincide with changes in the proximity of genetic relatives; it was predicted that individuals typically did not have close relatives residing nearby during those portions of the season when alarm calls were rarely given. The range over which the alarm vocalization is audible to ground squirrels was consequently determined, and compared with the average distance between home ranges of adult relatives.

\section{Materials and Methods}

The results reported below are based on data collected from June to October 1976, and from March to October 1977 and 1978. Thirteen-lined ground squirrels (Spermophilus tridecemlineatus) inhabiting a 5.2-ha portion of the University of Michigan's Matthaei Botanical Gardens were toe-clipped for permanent identification. For identification at a distance, the ground squirrels were marked on both sides of the body with Miss Clairol Black Velvet Hair Dye (Sherman 1976). Over the three years of study, the population. size ranged from 12 to 33 adults; the adult male-female ratio varied from $1: 2.0$ to $1: 3.4$. In addition to preliminary work during 1976 , more than 2,300 $\mathrm{h}$ were spent in the field during 1977 and 1978.

Most of the study site was bounded by unmowed areas, pond, marsh, or woodland. With the exception of a 0.6-ha tract, it was regularly mowed to a height of $50 \mathrm{~mm}$ and contained a variety of ornamental trees and shrubs. Red-tailed hawks (Buteo jamaicensis) were sighted 79 times on the study area; other potential predators (sighted fewer than 10 times each) included marsh hawks, Circus cyaneus, Cooper's hawks, Accipiter cooperii, and massasanga rattlesnakes, Sistrumus catenatus.

Alarm calling behavior was quantified by observation of ground squirrel reactions to (a) the approach or presence of avian predators, and (b) human and canine approaches. For a 'human approach,' a ground squirrel was sighted, identified, and directly approached until it entered a burrow. A Labrador retriever was brought to the study site approximately one morning a week for 'canine approaches' and trained to remain hidden with the observer until signaled to run toward a squirrel. The occurrence of audible vocalizations was recorded following each approach. On both human and canine approaches, the minimum initial distance to the squirrel was approximately $25 \mathrm{~m}$. One juvenile and one adult squirrel were captured by the dog.

Adult female home range samples are reported for two periods during the 1978 season: during pregnancy or lactation, and 3 5 weeks after emergence of litters from their natal burrows. Home range data for each individual were collected during $1 \mathrm{~h}$ of morning and $1 \mathrm{~h}$ of afternoon observation. The squirrel's location was recorded at 10-min intervals. Morning and afternoon activity of an individual were monitored on different days, observations were suspended during burrow excavation and nest material gathering, and morning sampling was not begun until squirrels had moved at least $1 \mathrm{~m}$ from their home burrow. Locations were recorded with respect to their direction and distance from mapped landmarks. A home burrow was defined as the burrow from which a squirrel first emerged in the morning.

Vocalizations were recorded in the field with a Nagra IV tape recorder and an AKG condenser microphone (CK-9). A General Radio 1933 sound level meter (impact setting, band A) was used to measure sound pressure levels. A taped series of three trills which had been elicited by the approach of a human was used to determine the audible range of the alarm vocalization. The playback intensity was approximately that of the trill as emitted by adults. The mean sound pressure level of the taped trills was $98 \mathrm{~dB}$, measured $30 \mathrm{~cm}$ from the speaker. The mean sound pressure level of six trills given by unconfined adults in the field was $100 \mathrm{~dB}$, measured $25-35 \mathrm{~cm}$ from the squirrel.

All audible range trials were conducted on calm days shortly after the emergence of juveniles from their natal burrows in 1978 . The observer and tape recorder were hidden and the recorder placed at ground level with the speaker aimed directly at the subject. Trials were initiated while ground squirrels were foraging. The behavior of the squirrel was observed during presentation of the stimulus and for 30 additional seconds. The criterion for judging audibility of the signal to the squirrel was predetermined by playback experiment results (P. Schwagmeyer and C. Brown, Conspecific reaction to alarm calls of Spermophilus tridecemlinea$t u s$, the thirteen-lined squirrel, unpublished work). A squirrel was assumed to have detected the trill sequence if its reaction included standing erect or running to a burrow entrance during the trial.

\section{Results}

\section{Human and Canine Approaches}

Emergence of the ground squirrels from hibernation occurred in March and April in 1977 and 1978; mating activity was observed in mid-late April or early May. Juvenile emergence occurred over approximately two weeks in June or July. Most adults were apparently in hibernation by late September of each year. In both 1977 and 1978, vocalizations were rarely elidited by the approach of a human or dog prior to juvenile emergence. During the two years, 39 canine approaches were made to females and 22 to males before litters first appeared aboveground. None of these elicited vocalizations. Males vocalized during $1.8 \%(2 / 111)$ of human approaches made during the same time period; females vocalized on $1.3 \%(3 / 236)$ of human approaches.

After juveniles emerged each season, adult females could be classified as nonparous ( $n=11$ cases in two years, 9 different females) as determined by absence of both litter emergence and prominent mammae, or parous ( $n=23$ cases in two years, 19 different females) if offspring were successfully reared to the emergence stage that season. Data for females $(n=5)$ which could not be classified according to the above criteria were eliminated from the analyses. Following emergence of the young, nonparous females and males continued to vocalize only rarely when approached by a human or dog. Audible vocalizations were never emitted by males during 39 canine approaches and 219 human approaches; nonparous females vocalized on $1.8 \%(2 / 109)$ of human approaches and on $4.3 \%(1 / 23)$ of canine approaches. Parous females, in contrast, emitted vocalizations during $34.5 \%(19 / 55)$ of canine approaches and $24.2 \%(65 / 269)$ of canine approaches made after juvenile emergence. Three-sample $\chi^{2}$ tests indicated that 


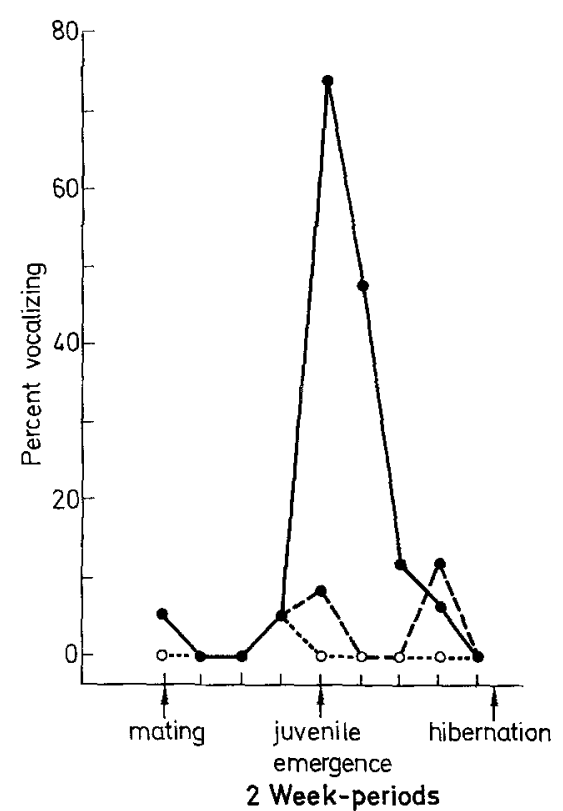

Fig. 1. Percentage of sampled individuals which vocalized on at least one human or canine approach during a two-week period. First 8 weeks: males (dotted line) and females (solid line); last 10 weeks: males (dotted line), parous females (solid line), and nonparous females (dashed line). Mean percentage of males within population sampled during each two-week period $( \pm S D)=81.7 \pm$ $19.2,7 \leqq n \leqq 13$ males; mean percentage of parous females within population sampled during each two-week period $=78.8 \pm 15.7$, $11 \leqq n \leqq 23$; mean percentage of nonparous females within population sampled during each two-week period $=81.0 \pm 15.7,6 \leqq n \leqq 11$ nonparous females

the frequency of vocalization by males, nonparous females, and parous females differed significantly on both human $\left(\chi^{2}=82.54, P<0.001\right)$ and canine $\left(\chi^{2}=22.50, P<0.001\right)$ approaches.

The relationships between incidence of approachelicited vocalizations and sex, reproductive status, and time are depicted in Fig. 1. The 1977 and 1978 field seasons were divided into nine two-week periods in which representative samples of both adult males and females could be obtained. Approach data were compiled separately for each individual adult; the percentage of sampled males and females (first eight weeks) or males, nonparous and parous females (last ten weeks) which vocalized at least once during a twoweek period is plotted. With the exception of a nonparous female which vocalized at one canine approach in 1978, all ground squirrels vocalizing at canine approaches were also emitting vocalizations when approached by a human. Human and canine approach data were therefore combined. Only parous females displayed any substantial fluctuation over time in the percentage of 'callers'; their peak in incidence of vo-

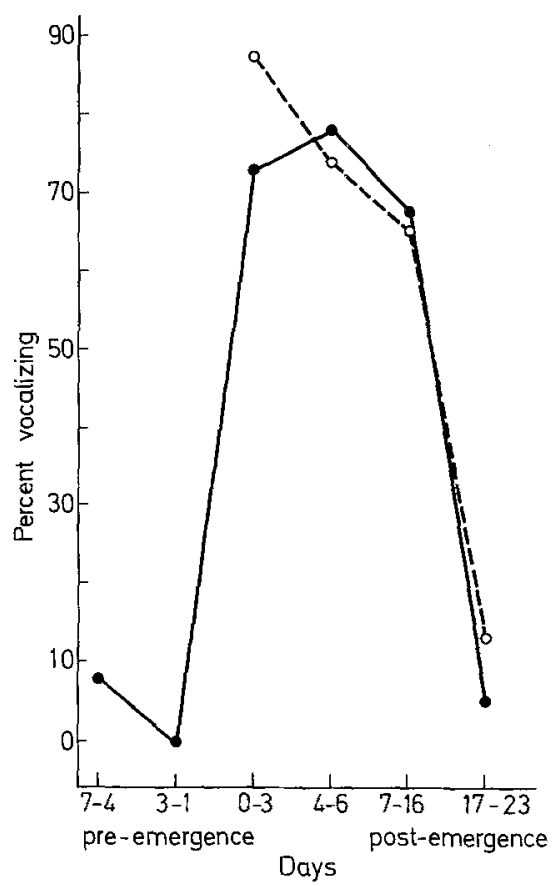

Fig. 2. Percentage of the sampled parous females (solid line) and litters (dashed line) which vocalized at the approach of a human or $\mathrm{dog}$ as a function of emergence time (day 0 is the first day the litter was observed aboveground). Mean percentage of parous females within population sampled during each time period $( \pm$ $\mathrm{SD})=75.7 \pm 19.6,12 \leqq n \leqq 22$ fernales; mean percentage of litters or portions of litters sampled during each time period $=52.2 \pm 20.4$, $8 \leqq n \leqq 17$

calization coincided with, and was restricted to, the four-week periods initiated by emergence of the first litter.

When the results of human and canine approaches to parous females are considered with respect to the emergence date of each individual's litter (Fig. 2), it can be seen that the percentage of mothers which vocalized increased abruptly with the emergence of their own litter. By the time their own litters had been aboveground 17-23 days, parous females no longer vocalized in response to a human or canine approach.

Juveniles also emitted vocalizations in response to human or canine approaches. Juvenile females vocalized on 9.3\% (17/182) of human approaches, and on $5.3 \%(1 / 19)$ of all canine approaches made prior to their first hibernation. Juvenile males vocalized on $8.3 \%(11 / 133)$ of human approaches; none vocalized during 23 canine approaches. There was no significant sex difference in frequency of vocalizing; there was also no significant difference in percentage of human versus canine approaches which elicited 
vocalizations from juveniles. Figure 2 displays the percentage of litters in which at least one juvenile vocalized at a human or canine approach, made in the absence of the mother, as a function of postemergence time: the decline in calling exhibited by parous females was paralleled by a concurrent decline in their offspring's tendency to vocalize.

The period during which alarm calls are given by mothers and young (Fig. 2) roughly corresponds with the postemergence association of mothers and their litters. Females were last observed with their litters from 1 to 20 days post-emergence $(\bar{x}=6.3, n=$ 18 ); five mothers were observed to have changed home burrows from that of their litters at 8-22 days post-emergence $(\bar{x}=14.2)$. Litters, or portions of litters, were last observed together at 6-35 days postemergence $(\bar{x}=15.2, n=17)$.

Unattended domestic dogs were observed on the study site on 14 occasions. Squirrels vocalized on five of these. A juvenile female and a parous female were identified as callers in two instances. Callers were not visible to the observer on the remaining three. On four occasions, adult females were observed to stand erect at the appearance of a dog, but not to vocalize. None of them had newly emerged offspring. Three juveniles and one adult male also failed to vocalize during these encounters. Though limited, the observations are consistent with the experimentally derived data.

Eighty-eight percent of the vocalizations emitted by squirrels on human approaches, and $96 \%$ of canine approach-elicited vocalizations, were identified as trills or a series of trills [Harris 1967; A. Kiss, The vocal behavior of the thirteen-lined ground squirrel (Spermophilus tridecemlineatus Mitchell) in Illinois, unpublished work]. The remainder of the vocalizations could not be confidently categorized, or consisted of other calls or trills in conjunction with other calls.

\section{Avian Predator Encounters}

Avian predator (B. jamaicensis, C. cyaneus, or A. cooperii) sightings $(n=89)$ yielded 29 direct observations of the reaction of ground squirrels to nearby hawks; vocalizations were not emitted by squirrels on any of these occasions. Trills were heard during two of 26 avian predator sightings which involved hawk flight over portions of the study site adjacent to the observer, but did not include direct monitoring of ground squirrel behavior. Ground squirrels did sometimes appear to react to hawk calls given by other species. For example, red-winged blackbird (Agelaius phoeniceus) avian predator calls were observed to be given in the presence of $S$. tridecemlineatus on seven
Table 1. Mean distances ( $\bar{x}$ in meters, $m$ ) between $A$ ) home ranges at minimum and maximum points of separation and $B$ ) home burrows of mothers and daughters or sisters simultaneously living on the study area before and 3-5 weeks after 1978 juvenile emergence. Percentage of mother-daughter or sister-sister pairs with home burrows and home ranges within audible range of the alarm call $(<75 \mathrm{~m})$ is indicated in far right column; $n=10$ pairs prior to juvenile emergence, 5 pairs following emergence

\begin{tabular}{|c|c|c|c|}
\hline & $\vec{x}$ & Range & $\begin{array}{l}\%< \\
75 \mathrm{~m}\end{array}$ \\
\hline \multicolumn{4}{|l|}{ A) Home range minima (distance) } \\
\hline Prior to juvenile emergence & 15.2 & $0-44.5$ & 100 \\
\hline Following juvenile emergence & 18.3 & $1.6-39.4$ & 100 \\
\hline \multicolumn{4}{|l|}{ Home range maxima (distance) } \\
\hline Prior to juvenile emergence & 70.9 & $38.2-135.8$ & 60 \\
\hline Following juvenile emergence & 69.9 & $56.2-94.4$ & 80 \\
\hline \multicolumn{4}{|l|}{ B) Home burrow distances } \\
\hline Prior to juvenile emergence & 50.1 & $19.1-119.4$ & 80 \\
\hline Following juvenile emergence & 51.8 & $25.0-70.2$ & 100 \\
\hline
\end{tabular}

occasions in June of 1978. Seven ground squirrels which had apparently been unaware of the approaching hawk stood erect or ran to burrows; four $S$. tridecemlineatus, however, displayed no detectable reaction to the calls.

\section{Population Structure}

Despite a slight male bias in captures of 1977 newly emerged young, only two of five yearling males versus 12 of 14 yearling females resident during some portion of 1978 were known to have been born on the study site. In 1978, at least nine yearling females (64.3\%) had either their mother or a female littermate living on the study area; Table 1 presents data on the spatial distribution of adult female relatives residing simultaneously on the study site in 1978. As indicated, the home ranges of yearling females, during portions of the season when alarm calls are rarely given, either overlapped or were adjacent to those of their female relative(s).

No parental care by males was observed, and males did not necessarily settle near their putative mates. Five of seven males which participated in 1978 mating were resident during juvenile emergence. Their home burrows were located $22-160 \mathrm{~m}(\bar{x}=88.2 \mathrm{~m})$ from those of females $(n=9)$ they had been observed to mount during estrus that season.

\section{Audible Range of the Alarm Call}

The audible range estimation is based on 23 playbacks of the trill sequence to ground squirrels $50-125 \mathrm{~m}$ 
distant from the speaker. Squirrels responded to the trills on all trials $(n=5)$ conducted at distances between 50 and $74 \mathrm{~m}$; they responded to only one of the five trials conducted at distances between 100 and $125 \mathrm{~m}$. The maximum audible range of the call was determined to lie between 75 and $99 \mathrm{~m}$; within that interval, six of the 13 trials elicited an appropriate behavioral response. Since transmission of a particular acoustic signal may be affected by the sender's orientation, environmental conditions, etc., the 75to $99-\mathrm{m}$ value should be regarded as a rough estimate.

The home burrow and home range proximity of adult female relatives are compared with the lower boundary of the estimated range of the trill $(75 \mathrm{~m})$ in Table 1. All females known to have an adult daughter, mother, or sister living on the study area in 1978 used areas within audible range of sites used by their relative. The sampled home ranges of the majority of mother-daughter or sister-sister pairs were, at all points, within the estimated range of the alarm trill.

\section{Discussion}

Human and canine approach-elicited calls in S. tridecemlineatus were most frequently given by mothers and their recently emerged offspring. Playback experiments have revealed that $S$. tridecemlineatus typically react to trills given shortly after juvenile emergence by either running to a burrow entrance or, if close to an entrance when the signal is presented, standing erect (Schwagmeyer and Brown, unpublished work). The conspecific reaction to the vocalization and the present results on the identity of callers thus support the hypothesis that $S$. tridecemlineatus alarm calling functions to warn relatives. The increased incidence of the behavior during the period of juvenile emergence, and its prevalence among mothers and their young, suggest that the warnings are directed primarily toward young offspring or littermates of the callers.

Maternal alarm calling at offspring emergence has been reported for other populations of $S$. tridecemlineatus: McCarley (1966) noted that the trill was commonly given by mothers upon the emergence of their young. Bailey (1893 p 33) commented that, 'During the breeding season these spermophiles are quiet and shy, but in June and July when their half-grown young begin to make their appearance above ground their voices are most frequently heard. The parent and her young at this time are constantly calling back and forth ...' Observations by both authors suggest that the seasonal changes in alarm calling reported here may be typical of the species. Recently emerged young probably are more vulnerable to predation than more mature squirrels; they would thus receive the maximum benefit from a warning (Maynard
Smith 1965). The onset of maternal calling, in particular, appears to be remarkably well adapted to the avoidance of predation upon juvenile offspring. While preemergent young may be vulnerable to predators entering their burrow (e.g., weasels, snakes), alarm calling would seem to be ineffective under such circumstances.

Alarm calling in $S$. tridecemlineatus appears to have at least one function, that of warning relatives, in common with the calling behavior of S. tereticaudus (Dunford 1977) and S. beldingi (Sherman 1977). However, S. beldingi and S. tereticaudus apparently warn adult as well as juvenile relatives. Sherman (1977) found no significant effect of time of year on terrestrial predator alarm calling in S. beldingi, and Dunford (1977) reported alarm calling prior to juvenile emergence in S. tereticaudus.

A second interspecific difference in calling behavior was revealed by the data on $S$. tridecemlineatus reaction to avian predators. The approach of hawks rarely evoked calls in this population of $S$. tridecemlineatus; the absence of a specific aerial predator call (Matocha 1977) or of detectable reactions to avian predators (Harris 1967) has been noted in other populations of this species as well. In contrast, the repertoire of some species of Spermophilus inchudes avian predator alarm calls which are distinct from those emitted in response to terrestrial predators $(S$. beldingi: Turner 1973; S. parryii: Melchior 1971; S. beecheyi: Fitch 1948 ; S. armatus: Balph and Balph 1966).

The usage of alarm calling by $S$. tridecemlineatus thus appears to be limited, relative to that of some members of its genus, in two respects: warnings of the approach of a human or dog are given only when newly emerged offspring or littermates of an individual are likely to benefit, and warnings of the presence of an avian predator are rarely given. Population structure would seem one plausible determinant of the prevalence of the behavior. If the primary function of alarm calling is to warn relatives, occurrence of the behavior should be contingent upon proximity of relatives. Calls should rarely be given when relatives are likely to have dispersed to areas beyond the audible range of the vocalization. It was predicted that, except during juvenile emergence, $S$. tridecemlineatus do not typically have relatives residing within the effective range of the vocalization.

To test this hypothesis, the audible range of the alarm call was compared with the spatial distribution of related individuals during portions of the season when calls are rarely given. The results indicated that females were indeed likely to have adult relatives residing on the study area, and that closely related females typically occupied areas within the effective range of the vocalization. If females had given alarm calls at the human, dog, or hawk approaches which 
occurred outside of the juvenile emergence portion of the season, they could have warned an adult relative.

These results suggest that the availability of relatives as recipients of a warning does not guarantee the evolution of alarm calling directed toward them. Theoretically, if a relative does not benefit sufficiently from a warning, or if the risks to the caller are too high, the behavior would not evolve (Hamilton 1963, 1964). Interspecific differences in factors such as agespecific mortality from predation (Wilbur et al. 1974), the acoustic structure of the vocalizations, or the safety of calling sites, through their effects on the benefits or costs of the behavior, may ultimately be responsible for the differential alarm calling behavior of Spermophilus species. Alternatively, the extent to which individuals of various species invest in close relatives by warning them of avian or terrestrial predators may be determined by the intensity of selection for any type of nepotism. As noted elsewhere (Schwagmeyer 1979), the degree to which females of some species of Spermophilus invest in relatives through alarm calling behavior seems to be correlated with the degree to which they tend to display other forms of preferential treatment of relatives. Interspecific variability in usage of alarm calling behavior to warn relatives may, therefore, be related to variability in intraspecific competition (Alexander 1974; Brown 1974), levels of inbreeding (Hamilton 1972, 1975), or other conditions which have been hypothesized to promote the evolution of nepotistic interactions.

Acknowledgements. I am grateful to R. Davis, R. Alexander, M. Beecher, C. Brown, W. Holmes, P. Sherman, and W. Stebbins for their advice on the research or manuscript. I thank B. Bond, J. DeNeff, and C. Florman for their field assistance, and the staff of the Botanical Gardens for their cooperation. Financial support was provided by an NIMH Predoctoral Fellowship and a Sigma Xi Grant-in-Aid-of-Research.

\section{References}

Alexander R (1974) The evolution of social behavior. Annu Rev Ecol Syst 5:325-383

Bailey V (1893) The prairie ground squirrels or spermophiles of the Mississippi Valley. US Dep Agric Div Ornithol Mammal Bull 4:1-67

Balph D, Balph D (1966) Sound communication of Uinta ground squirrels. J Mammal 47:440-450

Brown J (1974) Alternate routes to sociality in jays - with a theory for the evolution of altruism and communal breeding. Am Zool 14:63-80

Charnov E, Krebs J (1975) The evolution of alarm calls. Am Nat $109: 107-112$

Dawkins R (1976) The selfish gene. Oxford University Press, New York

Dunford C (1977) Kin selection for ground squirrel alarm calls. Am Nat 111:782-785

Fitch $H$ (1948) Ecology of the California ground squirrel on grazing lands. Am Midl Nat 39:513--596

Hamilton W (1963) The evolution of altruistic behavior. Am Nat 97:354-356

Hamilton W (1964) The genetical evolution of social behavior, I, II. J Theor Biol 7:1-52

Hamilton W (1972) Altruism and related phenomena, mainly in social insects. Annu Rev Ecol Syst 3:193-232

Hamilton W (1975) Innate social aptitudes of man: an approach from evolutionary genetics. In : Fox R (ed) Biosocial anthropology. Halsted Press, New York

Harris J (1967) Voice and associated behavior in Citellus tridecemlineatus and other ground squirrels. $\mathrm{PhD}$ thesis, University of Michigan

McCarley H (1966) Annual cycle, population dynamics and adaptive behavior of Citellus tridecemlineatus. J Mammal 47:294 316

Matocha K (1977) The vocal repertoire of Spermophilus tridecemlineatus. Am Midl Nat 98:482-487

Maynard Smith J (1965) The evolution of alarm calls. Am Nat 99:59-63

Melchior H (1971) Characteristics of arctic ground squirrel alarm calls. Oecologia (Berlin) 7:184-190

Perrins C (1968) The purpose of the high-intensity alarm call in small passerines. Ibis 110:200-201

Schwagmeyer P (1979) The function of alarm calling behavior in Spermophilus tridecemlineatus, the thirteen-lined ground squirrel. $\mathrm{PhD}$ thesis, University of Michigan

Sherman P (1976) Natural selection among some group-living organisms. PhD thesis, University of Michigan

Sherman P (1977) Nepotism and the evolution of alarm calls. Science 197:1246-1253

Trivers $R$ (1971) The evolution of reciprocal altruism. Q Rev Biol 46:35-57

Turner L (1973) Vocal and escape responses of Spermophilus beldingi to predators. J Mammal 54:990-993

Wilbur H, Tinkle D, Collins J (1974) Environmental certainty, trophic level, and resonrce availability in life history evolution. Am Nat 108:805-817

Williams G (1966) Adaptation and natural selection. Princeton University Press, Princeton 